\title{
On the Associations among Critical Thinking, Reflective Thinking, and Emotions: a Case of Iranian EFL Teachers
}

Tahereh Heydarnejad, Mohammad Reza Ebrahimi*, Hossein Najjari

Department of English, University of Gonabad, Gonabad, Iran

Corresponding Author: Mohammad Reza Ebrahimi, E-mail: rezaebrahimi2@yahoo.com

\section{ARTICLE INFO}

Article history

Received: April 05, 2018

Accepted: July 12, 2018

Published: November 01, 2018

Volume: 7 Issue: 6

Advance access: September 2018

Conflicts of interest: None

Funding: None

\begin{abstract}
The systematic process of gaining knowledge and skills through study and instructions which is called education is of an extreme importance for human being. Education can bring money, equality, independence, and ultimately a prosperous individual which in turn makes a prosperous society at least by economic growth for nations; not to mention that it paves the way for creating a safer world. In this almost mainstreamed trend of being fascinated by education, 'thinking' is said to be the Cinderella skill. In the current study, critical thinking, reflective thinking and also emotions were studied to uncover the probable interplay among them. The results of the analysis of questionnaires (Watson-Glaser's Critical Thinking Appraisal, Reflective Thinking Questionnaire, Emotions Questionnaire for Teachers) filled by 160 EFL teachers in Iran showed a significant relationship among them and almost all Critical Thinking subcomponents were predicting the other two variables. The findings of the study will help further the knowledge in educating in a broader view, and in the field of English Language teaching in a more narrow sense.
\end{abstract}

Key words: Critical Thinking, EFL Teachers, Emotions, Reflective Thinking

\section{INTRODUCTION}

Many scholars have delved into Critical Thinking (CT) issue and the probable links with other variables and its roles in success. Huitt (1998) argued that thinking has a substantial role in life success in the information age. Huitt also further adds that there is a new focus on thinking as an important component of success. This shift of attention calls for different issues like CT and reflective thinking which are associated with higher-order thinking skills. Based on the related literature and the definitions of $\mathrm{CT}$ and reflective thinking concepts, it is assumed in the current study that these two concepts could be related; furthermore as an educated guess, it was presumed that they can have interplay with emotions. Siegel (1988, p. 23) stipulated the two central components of CT conceptualization that are significant in schooling; one is "reason assessment components" and the other is the "critical spirit component of critical thinking or critical attitude". He argues that these components are crucial in possessing CT. Also, Lipman (1991) conceives of learning which is critical as a healthy skepticism, while Norris and Ennis (1989) think of it as a rational and reflective thinking based on choosing what must be done or believed. Likewise, Bensley (1998) explained it as "reflective thinking involving the evaluation of evidence relevant to a claim so that a sound conclusion can be drawn from the evidence" (p.5).

\section{The Importance of the Study}

While we never stop having the words move through our minds, it goes without saying that thinking is very crucial and higher order thinking skills could be a lot more crucial. Elder and Paul (1994) argued that the ability to think and to be in charge of one's own thinking process and to create criteria for scrutinizing and appraising thinking is a pivotal requirement of $\mathrm{CT}$.

On the other hand, for long it has been believed that emotions cannot be made separate from thinking process. In the realm of language teaching, many dominant methods and approaches have been criticized and diminished due to inattention to affections and learners feelings. From that time on, affection used to accompany cognition in teaching principles and axioms.

Brookfield (1987) emphasizes the centrality of emotion in critical thinking. He argued that "challenging unquestioned assumptions, looking skeptically at givens we have lived by, and trying to shake off habitual ideas and behaviors so that we can try out alternatives, are emotionally potent activities" (pp. 231-2; cited in Moon, 2008). In the same line of inquiry, Berg (2008) considered emotions as subjective, affective, and neurochemical phenomena effective on the psychological, physical, and cognitive systems. She believes that "emotions drive goals and are integrated with cognitive functions" (p. 94). Elder (1996) also claimed that critical thinking will 
successfully conduct beliefs and actions while it continually assesses emotional states, cognitive abilities, feelings, overt and hidden drives and plans. Having these standpoints in mind, the current research intends to shed some lights on the possible interplay among, $\mathrm{CT}$, emotions and reflective thinking among EFL high school teachers in Iran. To this end, research questions were put forth as follows:

Question 1. Is there any correlation between CT and Reflective thinking?

Question 2. Is there any correlation between CT and Emotions.

Question 3. Is there any correlation between Emotions and Reflective thinking.

To answer the research questions, the following hypotheses were posed:

Ho-1: There is no correlation between CT and Reflective thinking?

Ho-2: There is no correlation between CT and Emotions.

Ho-3: There is no correlation between Emotions and Reflective thinking.

\section{LITERATURE REVIEW}

The present research examined the relationship among EFL teachers' reflective thinking, CT, and emotions. Ebrahimi and Moa'fian (20012) claimed that "it appears that CT lurks behind much of the thinking about higher education and professional development. Now, this construct and its relation to the educational development seem to have emerged crucial".

\section{Critical Thinking}

Taking a glance at existing literature on CT indicates a disagreement on a unified definition; Minnich (1990) for instance, claims that it is a "mystified concept" (p. 5). In the same line of inquiry, Halanon (1995) asserts that CT scholarship's state is mystified. "No single definition of critical thinking is widely accepted" (p. 75). Fasko (2003) also believed that "there is no consensus on a definition of critical thinking" (p.8). It is worth highlighting that despite a great number of definitions on critical thinking, there is a consensus that CT can be effective approximately in various disciplines, and it is needed for fulfilling academic objectives (Facione \& Facione, 2006). Based on the existing research on $\mathrm{CT}$, higher education experts contend that it is a criterion for intellectual excellence needed for constructive and full contribution in educational lives of students and their social and individual lives as well (Scriven and Paul, 2004). Accordingly, it is concluded that a major objective of education is creating CT or improving critical thinking ability (Birjandi and Bagherkazemi, 2010; Bailin et al., 1999).

CT skills have attracted attention and some research studied the significance of improving higher-order thinking skills and the Critical Thinking positive impact on foreign language learning contexts achievement (e.g. MacBride \& Bonnette, 1995). In a similar vein, Elder and Paul (2003) explained that a significant role of educating CT is to change a student into an active questioner. As an example, Dewey (1933) argued that the main aim of teaching is to know how to think. Students shall cultivate and know the application of CT skills to the complicated affairs that they will encounter (Yeh, 2004), or the critical decisions they will have to make because of rapid technological changes and information explosion (Oliver \& Utermohlen, 1995). Smith (1990) argued that thinking critically is learned by children while they have the reason and time for thinking in critical ways, while they observe similar actions done by others and while they are allowed to enter an argument, a challenge based on respect rather than exploitation or power.

In a similar vein, Ivie (2001) defined CT as reflective practice which enables learners to "establish clear and logical connections between beginning premises, relevant facts, and warranted conclusions" (Ivie, 2001, p.10). Scriven and Paul (2004) defined critical thinking as, "the mode of thinking in which the thinker improves the quality of his or her thinking by skillfully taking charge of the structures inherent in thinking and imposing intellectual standards upon them".

\section{Reflective Thinking}

Reflection can offer a means to learners with which they can analyze and evaluate the process of learning and monitor their development. Fogarty (1994) utilized the notion of Reflective Thinking by the use of the term "metacognitive reflection" focusing on contributing teachers awareness of their own thought processes and those of their learners. 'reflection', or 'reflective thinking' were used by Dewey (1933) for the first time, who defined it as "active, persistent, and careful consideration of any belief or supposed form of knowledge in the light of the grounds that support it and the conclusion to which it tends" (p. 9). His influential ideas put emphasis on the significance of lived experience as a point of departure in learning. It is worth highlighting that, he conceived of reflective practice as an inquiry which is intentional, systematic, and disciplined which finally ends in professional growth and improvement for teachers (reflection-on-action). Donald Schön thereby putting flesh on the bones added to this the idea of a practitioner being able to reflect on his or her intuitive knowledge while engaged in the action of teaching (reflection-in-action). Besides, Schön argues on the existence of three forms of reflection: retrospective one, which is based on actions done in the past, anticipatory ones based on actions which will be done in the future, and contemporaneous ones or reflection in action (cited in: Bean \& Stevens, 2002).

Moon (2005) argued that reflection is a mental processing form used to reach a goal or to attain some predicted results. It is used in order to have a better grasp of related ideas which are complicated or scattered and is to a great extent based on knowledge reprocessing. Ultimately, it was explained as past experience response involving conscious recall and examination of the experience as a basis for evaluation and decision-making and as a source for planning and action (Mirzaeia, F., Aliah Phang, F., \& Kashefi, H., 2014).

\section{Emotions}

Emovere is the Latin origin of emotion which means to stir up, to move out (Hargreaves, 1998), which implies that 
every individual is moved or stirred up by their feelings. Student emotions has always been an area of concern (Pekrun, 2006) but teacher emotion is the all-to-often neglected issue. (Keller, Chang, Becker, Goetz, \& Frenzel, 2014). Considering the dearth of research in this domain, Van Veen and Lasky (2005) put emphasis on making use of emotions as a lens for looking at the teacher's identity and educational change, thus not only they could not be neglected but also they must be involved in every interpretations and results while studying humans cognitive processes. That is due to the fact that, positive and influential teaching is valued but it is not reachable without considering teacher emotions (Heydarnejad, Hosseini Fatemi, \& Ghonsooli, 2017). Hargreaves (1998) claimed that "emotions are at the heart of teaching" and "good teaching is charged with positive emotions" (p. 835).

To further prove that affection and cognition are related to each other and they could not be thought of as separate factors, Sutton and Wheatley (2003) argued that according to cognitive and social psychologists, teachers' cognitions are affected and shaped by emotions; consequently, emotions can have a significant influence on memory, attention, and categorization (Sutton \& Wheatley, 2003), goals and efficacy beliefs (Kaplan, Gheen, \& Midgley, 2002), motivation (Pekrun, Goetz, Titz, \& Perry, 2002).

In the same line of inquiry, Appraisal Theory which according to Chang (2009) takes a cognitive approach toward emotions is one of the main theories which can explain teachers' emotional experiences (Frenzel, Goetz, Stephen, \& Jacob, 2009). Frenzel et al. (2009) postulated five appraisals that are the main antecedents of emotions. Frenzel (2014) proposed a reciprocal model representing the interrelations between perceptions of teachers' emotions, students' behavior, appraisals, goals for achievement behavior, and teachers' instructional behaviors. From an achievement perspective the model studies teacher emotions and also addresses them from a particular outlook to teacher judgments based on the success or failure of their own teaching efforts. It is worth considering that appraisal theory and attribution theory are the theories on which the model is based and this theory demonstrates causes and effects of teacher emotions.

In the last few years, researchers and scholars reveal more attention to teachers' emotions as well as its relation with important factors of teaching. For instance, in a study by Becker, Keller, Frenzel, and Taxer (2015) antecedents of teachers' emotions were explored by using an intra-individual approach. Based on these findings, the antecedents were students' motivation and discipline; the emotions were teachers' enjoyment and anger. The mediating role of teachers' appraisals of goal conduciveness and coping potentials was also studied.

In another study, Khajavi, Ghonsooly and Hosseini Fatemi (2016) investigated motivations of EFL teachers for teaching and tested a burnout model based on motivations and emotions. Results showed that both emotions and motivations could predict various components of burnout, although, emotions were more influential than motivational factors. In a recent study, Heydarnejad, Hosseini Fatemi and
Ghonsooli (2017) explored EFL teacher's teaching styles preferences and emotional experiences as well as the possible relationship between teachers' teaching styles and their emotions. To this end, 200 EFL teachers from both public high schools and private language institutes of Iran took part in this study. According to the results, facilitator and delegator styles were the two most frequent styles endorsed by EFL teachers and regarding emotion, enjoyment was the most and anger was the least dominant emotions EFL teachers experienced in their classes. Furthermore, the findings showed significant correlations between teachers' teaching styles and their emotions.

\section{METHOD}

Participants who were selected by convenient sampling procedure and took part in the current correlational design study are introduced in the next section followed by explanations on the utilized instruments.

\section{Participants}

The subjects of the study were 208 high school EFL teachers in Khorasan-e-Razavi, Iran, who totally received 624 questionnaires (3 questionnaires were given to each participant). Yet 480 questionnaires were filled and 64 teachers did not like to participate in the study; thus, the teachers' profile goes as follows: 160 participants who were between 20 and 48 years old with 2 to 24 years of teaching experience. Out of 160 teachers, 73 were females and 87 males from different socio-economic backgrounds.

\section{Instruments}

Three questionnaires were used in the study and after filling them, a number of participants were randomly selected and interviewed in order to ensure the reliability of their answers. The questionnaires will be explained in further details.

\section{Watson-glaser's critical thinking appraisal (Form A)}

For the purpose of measuring teachers' critical thinking, the Watson-Glaser Critical Thinking Appraisal (CTA) (Form A) was administered. It includes 80 items and includes five subtests as follows: Inference, Recognizing Deduction, Interpretation, and Evaluation.

Test Reliability was determined in different ways: the scores' correlation on the alternate forms, their stability over time and the estimates of the test's internal consistency. Internal consistency was measured through utilizing split-half reliability coefficients administering the Spearman-Brown formula. The test was administrated to the same group with an interval difference to test stability over time. Results indicated an acceptable level of stability (0.73). The Watson-Glaser translated version in Persian of the test was applied. About the reliability and validity of the questionnaire in Iranian culture, Mohammadyari (2002) claimed that the test and subscales have it. The reliability of 0.98 was found for it. 


\section{Reflective thinking questionnaire (RTQ)}

The RTQ which was developed by Kember et al. (2000), has 16 items that describe four types of reflective thinking which Mezirow (1991) advocates. The estimates of reliability range from .58 to .74 for the 4 subscales of the RTQ, according to Leung and Kember (2003). The questions must be answered on a seven-point likert-scale from 1 ("definitely agree") to 7 ("definitely disagree").

\section{Emotions questionnaire for teachers (EQT)}

Frenzel, Pekrun, and Goetz (2013) designed and validated the Emotions Questionnaire for Teachers (EQT) and used it to measure anxiety, enjoyment, and anger. Moreover, by reviewing the literature, Khajavi, Ghonsooly, and Hosseini Fatemi (2016) developed items for pride, shame, and boredom. The emotions are assessed by 4 items on a six-point Likert type scale which ranges from 'strongly disagree' to 'strongly agree'.

\section{RESULTS}

Results of the study are as follows:

Based on Figure 1. all of the CT components have a significant predictive power on Emotions because $t$ values exceed 1.96 for all. Also, all of the CT components have a significant predictive power on reflective thinking as $t$ values exceed 1.96 for all of them, except for Recognizing Unstated Assumptions which did not show any predictive power as $t$ value for this component's predictive power for Reflective Thinking was 1.764 which is lower than 1.96.

Based on the Figure 2. all of the CT components have a significant predictive power on Emotions as the values are positive except for Recognizing Unstated Assumptions which does not have a significant predictive power. Based on Tables 4.1 and 4.2. it could be claimed that inference $(\beta=.294, t=10.733)$, Recognizing $(\beta=.229, t=9.522)$, Deduction $(\beta=.249, t=10.405)$, Interpretation $(\beta=.262, t=10.213)$, and Evaluation $(\beta=.286$, $t=11.990)$ have significant predictive power on Emotions.

It also could be stated that inference $(\beta=.230, t=3.375)$, recognizing $(\beta=.122, t=1.764)$, deduction $(\beta=.238, t=3.348)$, interpretation $(\beta=.247, t=3.798)$, and evaluation $(\beta=.218, t=3.291)$ have a significant predictive power on reflective thinking.

As the Table 1. shows significant relationships were found between Reflective Thinking with inference $(r=0.606$, $p<0.05)$, Recognizing $(r=0.142, p>0.05)$, Deduction $(r=0.637, p<0.05)$, Interpretation $(r=0.588, p<0.05)$.

The findings also showed significant relationships between Emotion with Reflective Thinking $(r=0.585, p<0.05)$, inference $((r=0.758, p<0.05)$, Recognizing $(r=0.728$, $p<0.05)$, Deduction $(r=0.763, p<0.05)$, Interpretation $(r=0.708, p<0.05)$, Evaluation $(r=0.731, p<0.05)$.

\section{DISCUSSION}

Emotion affects almost all parts of our lives. They change the way people think and act. Teachers as the heart in the

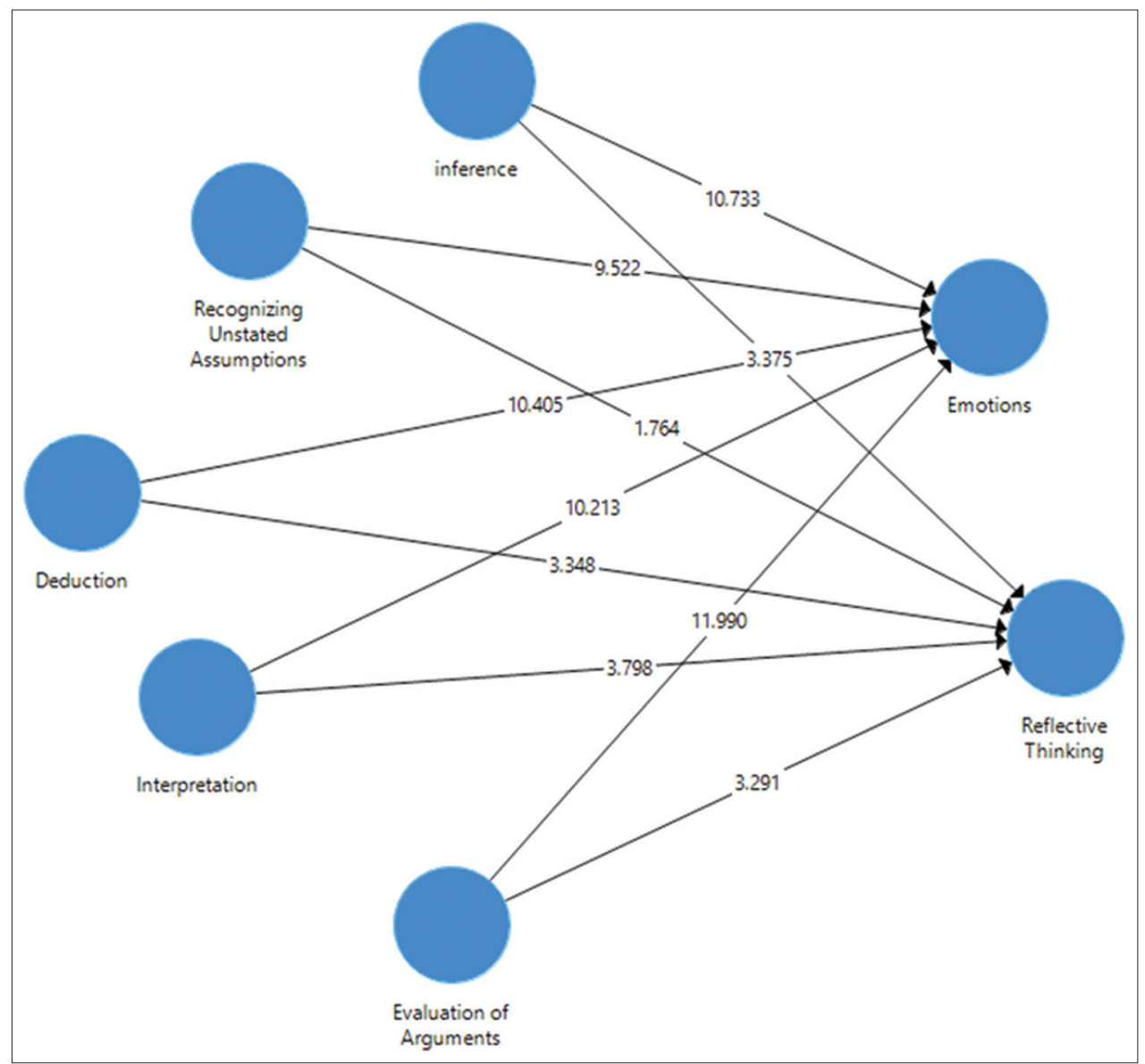

Figure 1. Schematic representation of t-values for the impacts CT on Emotions and Reflective thinking 


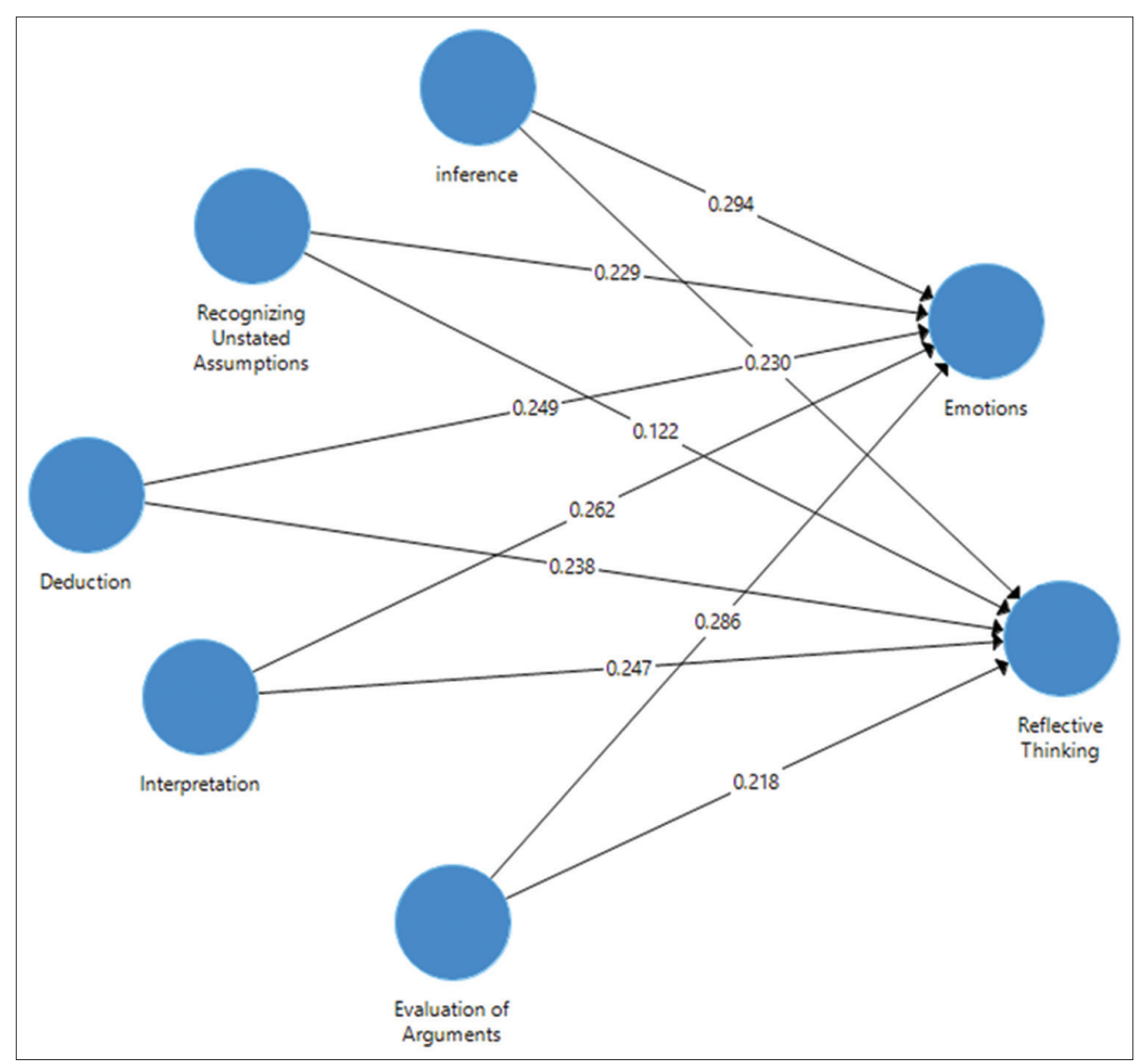

Figure 2. Schematic representation of the effects of CT components on Emotions and Reflective Thinking $(\beta)$

Table 1. Correlations between CT components and reflective thinking

\begin{tabular}{|c|c|c|c|c|c|c|c|}
\hline & Inference & $\begin{array}{c}\text { Recognizing } \\
\text { unstated }\end{array}$ & Deduction & Interpretation & Evaluation & Emotions & R.T \\
\hline \multicolumn{8}{|l|}{ Inference } \\
\hline Pearson Correlation & 1 & & & & & & \\
\hline \multicolumn{8}{|l|}{ Sig. (2-tailed) } \\
\hline Recognizing Unstated & & 1 & & & & & \\
\hline Pearson Correlation & $0.514 * *$ & & & & & & \\
\hline Sig. (2-tailed) & 0.000 & & & & & & \\
\hline \multicolumn{8}{|l|}{ Deduction } \\
\hline Pearson Correlation & $0.498 * *$ & $0.514 * *$ & 1 & & & & \\
\hline Sig. (2-tailed) & 0.000 & 0.000 & & & & & \\
\hline \multicolumn{8}{|l|}{ Interpretation } \\
\hline Pearson Correlation & $0.420 * *$ & $0.331 * *$ & $0.486^{* *}$ & 1 & & & \\
\hline Sig. (2-tailed) & 0.000 & 0.000 & 0.000 & & & & \\
\hline \multicolumn{8}{|l|}{ Evaluation } \\
\hline Pearson Correlation & $0.414 * *$ & $0.460 * *$ & $0.476^{* *}$ & $0.409 * *$ & 1 & & \\
\hline Sig. (2-tailed) & 0.000 & 0.000 & 0.000 & 0.000 & & & \\
\hline \multicolumn{8}{|l|}{ Emotions } \\
\hline Pearson Correlation & $0.758 * *$ & $0.728 * *$ & $0.763 * *$ & $0.708 * *$ & $0.731 * *$ & 1 & \\
\hline Sig. (2-tailed) & 0.000 & 0.000 & 0.000 & 0.000 & 0.000 & & \\
\hline \multicolumn{8}{|l|}{ R.T } \\
\hline Pearson Correlation & $0.606^{* *}$ & 0.142 & $0.637 * *$ & $0.588^{* *}$ & $0.585^{* *}$ & $0.807 * *$ & 1 \\
\hline Sig. (2-tailed) & 0.000 & 0.087 & 0.000 & 0.000 & 0.000 & 0.000 & \\
\hline
\end{tabular}


educational contexts could affect their students' physical and mental well-being. There are also often times that teachers are required to regulate their own emotions and feelings. So, a better understanding of the emotions' role in teaching can assist teachers to be well equipped to achieve the goal of educating students and tackle the demands of the classroom (Fried, 2011).

Consistent with the above argument, the two principal thinking skills -critical thinking and reflective thinking- can help teachers manage their emotions. Actually, they enable teachers to monitor themselves in order to take charge of their emotions and feelings. In the same vein RT as Moon (2008) asserted is a mental processing form that enables teachers to understand relatively complicated or unstructured ideas better. Thus, it seems plausible to presume that, reflective thinking helps teachers to actively take part in the critical thinking process and self-monitoring themselves which in turn leads to control of their emotions.

As Elder (1996) claimed that human mind involves three main functions at least, including feelings and cognition, the researchers of the current study sought probable relationships between emotions, CT and reflective thinking. Elder further argues that in each processing these functions have a dynamic relation and consequently thinking accompanies feeling. The results of the current study confirm Phan's findings (2007) that CT is related to reflective thinking. Berg's (2008) view considering cognition and affect relationship is in line with the current study. He claims that these mental mechanisms shall not be made separate. Berg (2008, p. 94) states that "Cognition without emotional motivation is meaningless and emotions should be re-harnessed through cognition".

De Bono (1982, p. 99) in the same line of inquiry and in harmony with the findings of the current study stated that "in the end all thinking is emotional .... In the end our decision, choices and courses of action are all determined by emotions, feelings and values. The purpose of thinking is to serve us as human beings, and feelings are the best judge of the effectiveness of that service" (cited in Moon, 2008). The findings of the present study are in accordance with empirical studies (Leung \& Kember, 2003; Phan, 2006).

The findings of the current study confirm Khajavi, Ghonsooly and Hosseini Fatemi (2016) and also Heydarnejad, Hosseini Fatemi and Ghonsooli (2017) who explored EFL teacher's teaching styles preferences and emotional experiences along with the possible relationship between teaching styles and their emotions. As it could be seen from the results, three posed research questions of the study are answered. There are significant relationships among CT, RT and emotions.

\section{CONCLUSION}

As a form of higher order cognitive engagement, thinking especially $\mathrm{CT}$ and reflective thinking plays as an auxiliary and powerful tool which raises awareness. According to the findings of this article, successful and meaningful education is after empowering teachers (and also students) with CT and RT skills. This ambition will not be far-fetched and will be fulfilled by emotionally intelligent teachers who are critical and reflective thinkers. The implications of the study could be adding some in-service classes for language teachers to make them familiar with CT and also make them familiar with Reflective Thinking and Emotions and their use in the world of language teaching and learning. Some workshops for students even may be of help. The current study was limited to teachers as participants, only. It could be replicated with a wider population and participants from various professions to ensure more generalizability of the results.

\section{REFERENCES}

Bailin, S., Case, R., Coombs, J. \& Daniels, L. (1999). Common misconceptions of critical thinking. Journal of Curriculum Studies, 31 (3), 269-283.

Bean, T. W., \& Stevens, L. P. (2002). Scaffolding reflection for pre-service and in-service teachers. Reflective Practice, 3, 205-218.

Becker, E. S., Keller, M. M., Goetz T., Frenzel A. C., Taxer J. L. (2015). Antecedents of teachers' emotions in the classroom: an intraindividual approach. Frontiers in Psychology, 6, 635.

Bensley, D. A. (1998). Critical thinking in psychology: A unified skills approach. Pacific Grove, CA: Brooks/ Cole.

Berg, C. V. D. (2008). A creative drama program to stimulate emotional intelligence in 10 to 11 year-old English speaking girls. Unpublished master's thesis, Tshwane University of Technology.

Birjandi. P., \& Bagherkazemi M. (2010). The relationship between Iranian EFL teachers' critical thinking ability and their professional success, English Language Teaching, 3(2), 135-145.

Chang, M. L. (2009). Teacher emotion management in the classroom: Appraisals, regulation, and coping with emotions. Unpublished dissertation.

De Bono, E. (1982). de Bono's thinking course. London: BBC Book.

Dewey, J. (1933). How we think. Chicago: Henry Regnery.

Ebrahimi, M. R., \& Moa'fin, F. (2012). Does emotional intelligence or self-efficacy have something to do with high school English teachers' critical thinking, considering demographic information? International Journal of Linguistics, 4(4), 224-242.

Elder, L. (1996). Cognition and affect: Critical thinking and emotional intelligence. Inquiry: Critical thinking across the disciplines, XVI (2). [Online] Available: http://www. criticalthinking.org/articles/ct-emotional-intelligence. cfm (May, 2018)

Elder, L., \& Paul, R. (2003). Critical thinking: Teaching students how to study and learn (Part IV). Journal of Developmental Education, 27(1), 36-37.

Facione, N. C., \& Facione, P. A. (1996). Externalizing the critical thinking in knowledge development and critical judgment. Nursing Outlook, 44(3), 129-136.

Fasko, D. (2003). Critical thinking: origins, historical development, future direction. In D. Fasko (Ed.), Critical 
thinking and reasoning: Current research, theory and practice (pp.3-20). Cresskill, NJ: Hampton Press.

Frenzel, A. C. (2014). Teacher emotions. In L. Linnenbrink-Garcia \& R. Pekrun (Eds.), Handbook of emotions in education (pp. 494-519). New York: Routledge.

Frenzel, A. C., Goetz, T., Stephens, E. J., \& Jacob, B. (2009). Antecedents and effects of teachers' emotional experiences: an integrated perspective and empirical test. In P. A. Schutz, \& M. Zembylas (Eds.), Advances in teacher emotion research: The impact on teachers' lives. New York: Springer.

Halonen, J. S. (1995). Demystifying critical thinking. Teaching of Psychology, 22, 75-81.

Hargreaves, A. (1998). The emotional practice of teaching. Teaching and Teacher Education, 14(8), 835-854.

Heydarnejad, T., Hosseini Fatemi, A., \& Ghonsooly, B. (2017). An Exploration of EFL Teachers' Teaching Styles and Emotions. Journal of Applied Linguistics and Language Research, 4(2), 26-46.

Heydarnejad, T., Hosseini Fatemi, A., \& Ghonsooly, B. (2017). Emotions and Self-regulation: A Case of Iranian EFL High School and Private Language Institute Teachers. International Journal of Educational Investigations, 4(4), 82-100.

Huitt, W. (1998). Critical thinking: An overview. Educational Psychology Interactive. Retrieved March, 2009, from http://chiron.valdostaedu/whuitt/col/cogsys/critthnk. html. [Revision of paper presented at the Critical Thinking Conference sponsored by Gordon College, Barnesville, GA, March, 1993.]

Ivie, S. D. (2001). Metaphor: a model for teaching critical thinking. Contemporary Education, 72(1), 18-23

Kaplan, A., Gheen, M., \& Midgley, C. (2002). Classroom goal structure and student disruptive behavior. British Journal of Educational Psychology, 72(2), 191-211.

Keller M. M., Chang M. L., Becker E. S., Goetz T., Frenzel A. C. (2014). Teachers' emotional experiences and exhaustion as predictors of emotional labor in the classroom: an experience sampling study. Front. Psychol. 5:1442. 10.3389/fpsyg.2014.01442

Kember, D., Leung, D., Jones, A. \& Loke, A. Y. (2000). Development of a Questionnaire to measure the Level of Reflective Thinking. Assessment and Evaluation in Higher Education, 25, 380-395.

Khajavi, Gh. H., Ghonsooly, B., \& Hosseini Fatemi, A. (2016). Development and validation of the Persian scale of EFL teachers' emotions. The Journal of Language and Translation Studies. Tesol Quarterly 50(1), 154-180.

Leung, D. Y. P., \& Kember, D. (2003). The relationship between approaches to learning and reflection upon practice. Educational Psychology, 23, 61-71.

Lipman, M. (1991). Thinking in Education, Cambridge University Press.
MacBride R. \& Bonnette R. (1995) Teacher and at risk students' cognitions during open-ended activities: Structuring the learning environment for critical thinking, Teaching and Teacher Education, 11(4) 373-388.

Mezirow, J. (1991) Transformative dimensions of adult learning, San Francisco, Josey-Bass.

Minnich, E. (1990). Transforming knowledge. Philadelphia: Temple University Press.

Mirzaeia, F. \& Phangb, F. A. \& Kashefi, H. (2014).Measuring Teachers Reflective Thinking Skills. Procedia - Social and Behavioral Sciences, 141, 640 - 647

Moon, J. (2005). Progression in higher education: a study of learning as represented in level descriptors, in P. Hartley, A. Woods and M. Pill (eds), Enhancing Teaching in Higher Education, London, Routledge

Moon, J. (2008). Critical thinking: An exploration of theory and practice. London and New York: Routledge.

Norris, S. P., \& Ennis, R., (1989). Evaluating critical thinking. Pacific Grove, California: Critical Thinking Press and Software.

Pekrun, R., Goetz, T., Titz, W., \& Perry, R. P. (2002). Academic emotions in students' self- regulated learning and achievement: A program of qualitative and quantitative research. Educational Psychologist, 37(2), 91-105.

Phan, H. (2006). Examination of student learning approaches, reflective thinking, and epistemological beliefs: A latent variables approach. E. Journal of Research in Educational Psychology, 4(3), 577-610.

Phan, H. P. (2007). An examination of reflective thinking, learning approaches, and self-efficacy beliefs at the university of the South Pacific: A path analysis approach. Educational Psychology, 27(6), 789-806. http://dx.doi. org/10.1080/01443410903289423

Phan, H.P. (2010). Critical thinking as a self-regulatory process component in teaching and learning. Psicothema, 22(2) 284-292.

Scriven, M., \& Paul, R. (2004). Defining Critical Thinking. [Online] Available: http://www.criticalthinking.org/ aboutCT/definingCT.shtml (May, 2018).

Siegel, H. (1988). Educating reason: Rationality, critical thinking and education. New York: Routledge \& Metheun.

Smith, F. (1990). To think. New York: Teachers College Press.

Sutton, R., \& Wheatley, K. (2003). Teachers' emotions and teaching: A review of the literature and directions for future research. Educational Psychology Review, 15(4), 327-358. http://dx.doi.org/10.1023/A:1026131715856

Van Veen, K., \& Lasky, S. (2005). Emotions as a lens to explore teacher identity and change: Different theoretical approaches. Teaching and Teacher Education, 21(8), 895-898. http://dx.doi.org/10.1016/j.tate.2005.06.002

Yeh, Y.C. (2004). Nurturing reflective teaching during critical-thinking instruction in computer simulation program, Computers and Education, 42(2)181-194. 